\title{
NAO-Teach: helping kids to learn societal and theoretical knowledge with friendly human-robot interaction
}

\author{
Ahmad Hoirul Basori \\ Faculty of Computing and Information Technology Rabigh, King Abdulaziz University, Saudi Arabia
}

\begin{tabular}{l} 
Article Info \\
\hline Article history: \\
Received Dec 1, 2019 \\
Revised Jan 20, 2020 \\
Accepted Feb 1, 2020 \\
\hline
\end{tabular}

\section{Keywords:}

Character Recognition

Child Education

Edutainment

Intelligence

Robotics

\begin{abstract}
Robotic technology has affected the education field, and even early education involves robot to attract Kids. Technical education is the notion of giving students knowledge of robots and technology. The main contribution of our research is to provide an interactive way of learning for kids through play and fun method. Two approaches proposed here: first, we provide an interactive game by touching robots body parts to teach kids how they were practising their motoric nerve and the listening to the instruction. In this game, kids asked to find some robot parts such as right hand, or left hand, where it equipped with a tactile sensor. The game difficulty can be increased by setting up the time limit for the answer and make kids touch the body parts of the robot very fast. The second learning method is practising number counting and pronunciation with NAO Robots. The robots will do computer vision processing to analyse and pronounce the kids handwriting with an artificial neural network. The result of implementation has obtained more than $75 \%$ success rate on recognition part with loss es than 0.6 . The system received strong appreciation from kids and their parent, while this research believed able to attract kids to study in interactive and fun ways.
\end{abstract}

Copyright $(\odot) 2020$ Institute of Advanced Engineering and Science. All rights reserved.

\section{Corresponding Author:}

\author{
Ahmad Hoirul Basori, \\ Department of Information Technology, \\ Faculty of Computing and Information Technology Rabigh, \\ King Abdulaziz University, Rabigh, Makkah, Saudi Arabia 21911. \\ Email:abasori@kau.edu.sa
}

\section{INTRODUCTION}

Robots recently already used widely in several aspects of our life, and most of the robot services are in the industry [1]. However, robots slowly integrate into the daily life of a human, and they will adapt to the activities in school, home, etc. Its will give an impact on the kid's social life and scholarly progress. As a concern, better thoughtfulness must be imposed on top of in what way robots can be part of the education system and assimilated with children live [2]. The advance of technology makes enhance the possibility of robots as a useful tool for learning process, and it can be used to teach computers parts, electronics, machine and linguistic [3]. Based on the current study, kids tend to perform superior on post-education examination, and they are more attracted to the robots rather than books or tape. It's because of Children see the robot as new things that used as "toys" for studying the language [4].

The goal of this research is to produce a robotic application that can help kids to make social interaction as well as develop early skills such as counting number and alphabet pronunciation. Nowadays, Autism kids also involved studying with the robot because of robots is considered as educational material such as LEGO Mindstorm for teaching logic and simple programming [5]. Social robotics also become attention when robots have equipped with emotional expression and can provide more attractive interaction. Some advanced countries use various robots in every sector: industry, military, education, medical, etc., Australia, German, Japan, Korea, United States of America and Netherland [6-10]. 
A robot used with intention introduce information technology and program design and to train scholar students with machinery [11]. In Dutch high school, students were progressively taught with practical topics using robots [12]. Study plan typically comprises first a preliminary outline to robotic programming and students apply their understanding principally by building their robots [13-15]. The starter stage usually helps when the students or even the academic arrangement is inexperienced with robot usage in teaching. The student who creates the robot will have tight possession then increase the attention of students [12]. They can bring and play with their robots at home, e.g., in Macquarie University Australia, they made kids converse the idea of rotations and transformations using the robot [8].

The path route of the robot is for teaching angles and geometry. Other cases of robot utilization in education are teaching kids kinematics and song instrumentation with the robot in Korea [16-17]. Another area is the exploitation of robotics application to demonstrate foreign linguistic, e.g., English was educated to children in Japan by "Robovie" in Kyoto [9] as well as Taiwan [17]. In term of emotional expression, some researcher has to conduct observation toward humanoid robot walking, and agent behaviour inside the crowd. These emotional behaviour are essential toward robotic realism where they can mimic the real human when performing interaction [18-22].

This research aims to use a robot for teaching kids through Game and character recognition. The first Game will help student on listening to English language. In contrast, the second application will make interaction with a student by pronouncing the character that kids has written in the paper.

\section{RESEARCH METHOD}

Children can choose two learning methods, and whether they want to play with the touch game or they can write a number in white paper and show to Nao, then Nao will capture the image and start to analyse the character.

Materials:

1) Material for experiments: Nao Robots with sonar, bump and tactile sensor. Camera for computer vision and speaker for speaking features, Nao also have a mic to capture the voice command from the student.

2) Computer with high-end Processor and Graphics for processing. The detail of NAO sensor is depicted in Figure 1.

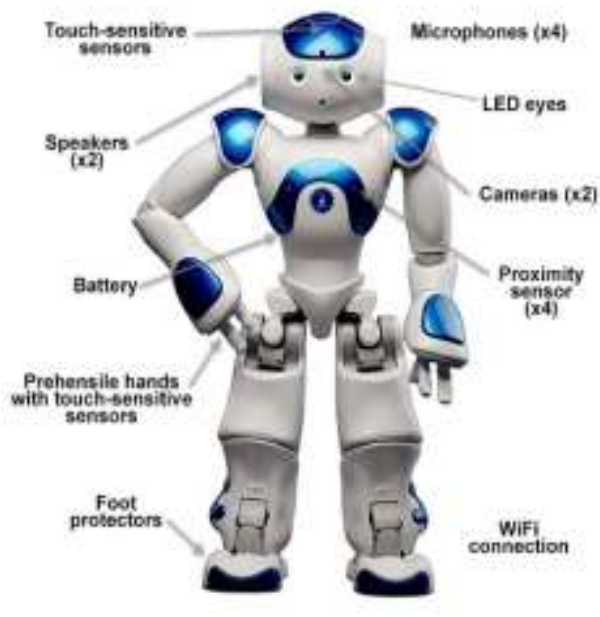

(a)
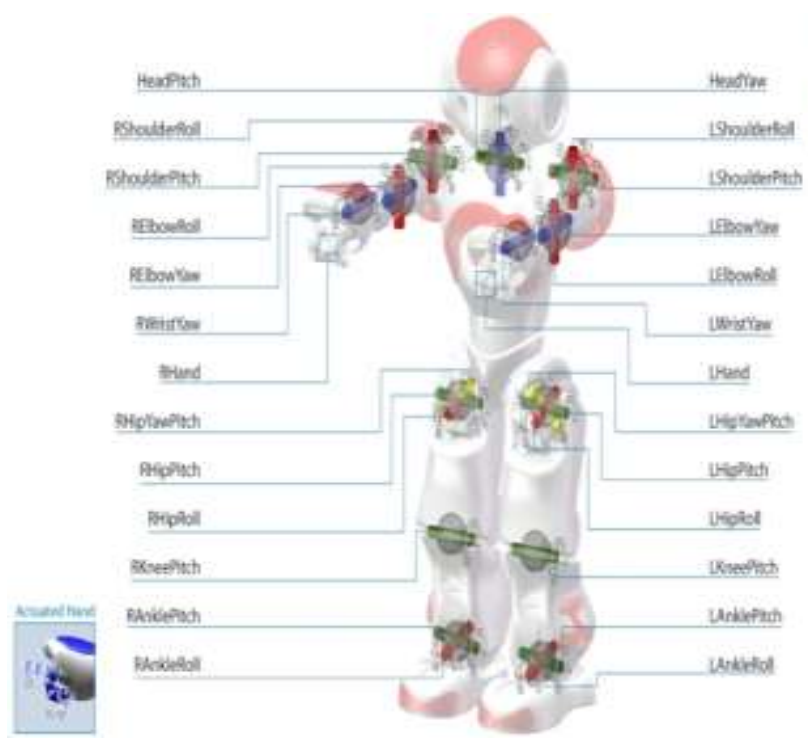

(b)

Figure 1. NAO Sensor, Image courtesy of Alysis [23], NAO actuator and sensor image courtesy aldebaran [24]

With numerous sensor, NAO is capable of responding with a simple conversation with kids by merely waving his hand and say "hello" and he also capable of making simple response such as "I'm good, how about you" etc. The NAO robot will speak the recognised character. The recognition will use an artificial neural network for the recognition process. The body touch required sensor stimulation for initiating action such as applauding if the answer correct and ask to touch the right sensor again. The kids will have two ways of 
communication with the robot that can enhance the immersion of learning for the Kids. The methodology of the project is consist of three main processes, as shown in Figure 2.

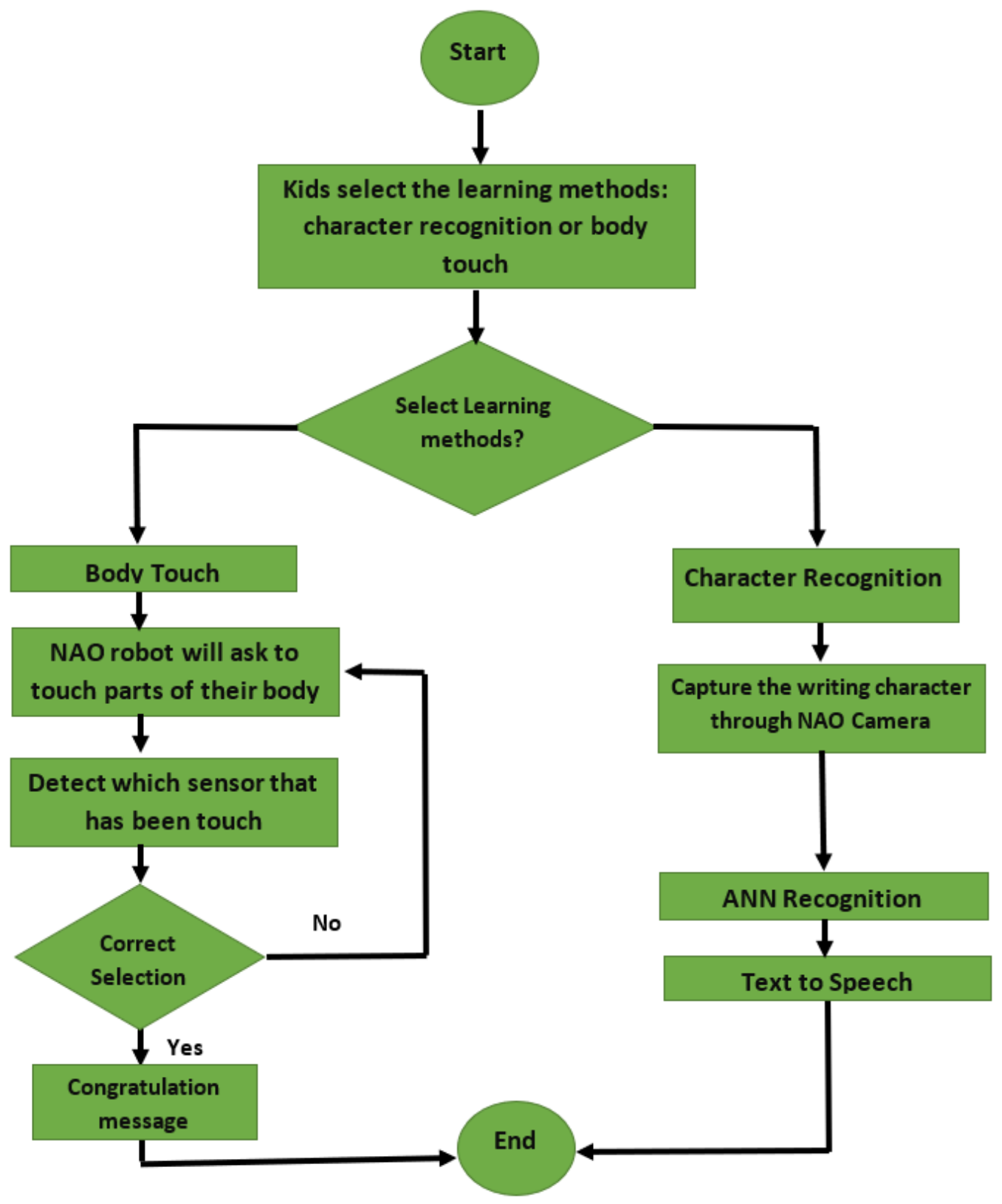

Figure 2. Methodology of NAO-Teach

\section{RESULTS AND DISCUSSION}

The proposed research aims to strengthen the kid's mind and their motoric function, and the first stage is encouraging their motoric by receiving instruction through hearing and optic nerve. Their motoric will be executed when they did with the observation and thinking process. This research has two main features which are capable of providing the kids with fun educational tools:

\subsection{Motoric Challenge for kids}

Kids will be asked to touch a part of the robot's body, and then the robot will verify whether the kids touch the correct sensor or not. If the answer right, Nao will give applause and appreciation to kids with a happy expression, however, if the answer not correct, nao will ask kids to choose the accurate sensor to be touched. These practices will influence children knowledge toward human body anatomy because NAO is kind 
of humanoid robot which resembles the human body parts itself. These practices can help kids to practice their listening of English words and their motoric nerve to locate the precise sensor. Figure 3 shows the demonstration of touch my head game. Refer to Table 1 for conversation between NAO and kids.

Table 1. Learning Conversation between Nao and Kids

\begin{tabular}{|c|c|c|}
\hline Tasks & Scenario & Affected Motoric/ Nerve \\
\hline Game Selection & $\begin{array}{l}\text { Kids will be welcomed by NAO by introducing } \\
\text { his name and the way of game being played. E.g. } \\
\text { Phrase "Hello Kids, My Name NAO, Nice to meet } \\
\text { you. We will played together nicely" }\end{array}$ & $\begin{array}{c}\text { Hearing } \\
\text { Visual } \\
\text { Haptic/Sense of touch }\end{array}$ \\
\hline Touch Nao head & $\begin{array}{l}\text { Kids will be asked to touch Nao Forehead. } \\
\text { "Kids, touch my head" }\end{array}$ & $\begin{array}{c}\text { Hearing } \\
\text { Visual } \\
\text { Haptic/Sense of touch }\end{array}$ \\
\hline Touch Nao Left Hand & $\begin{array}{l}\text { Kids will be asked to select Nao Lefh hand } \\
\text { "Kids, touch my left hand" }\end{array}$ & $\begin{array}{l}\text { Hearing } \\
\text { Visual } \\
\text { Haptic/Sense of touch } \\
\text { Sensory Neuron }\end{array}$ \\
\hline Touch Nao Right Hand & $\begin{array}{l}\text { Kids will be asked to select Nao Right hand } \\
\text { "Kids, touch my right hand" }\end{array}$ & $\begin{array}{l}\text { Hearing } \\
\text { Visual } \\
\text { Haptic/Sense of touch } \\
\text { Sensory Neuron }\end{array}$ \\
\hline Touch Nao Right Foot & $\begin{array}{l}\text { Kids will be asked to select Nao Right Foot } \\
\text { "Kids, touch my right foot" }\end{array}$ & $\begin{array}{l}\text { Hearing } \\
\text { Visual } \\
\text { Haptic/Sense of touch } \\
\text { Sensory Neuron }\end{array}$ \\
\hline Touch Nao Left Foot & $\begin{array}{l}\text { Kids will be asked to select Nao Left Foot } \\
\text { "Kids, touch my left foot" }\end{array}$ & $\begin{array}{l}\text { Hearing } \\
\text { Visual } \\
\text { Haptic/Sense of touch } \\
\text { Sensory Neuron }\end{array}$ \\
\hline
\end{tabular}

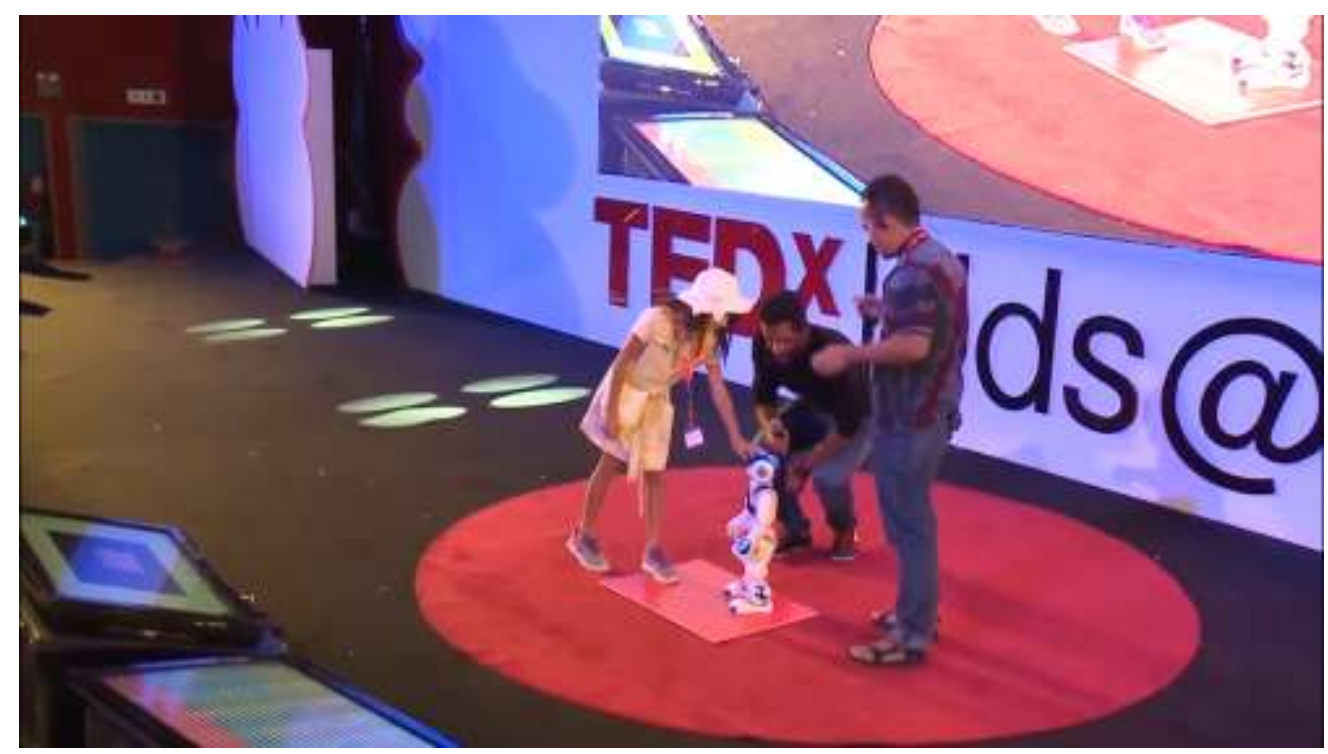

Figure 3. Kids are asking to do interaction with $\mathrm{NaO}$

While Figure 4 shown the choregraphe implementation to control the NAO a robot movement, how it moves, respond and receive stimulation. NAO will respond when kids touch one of NAO body parts such as hand, leg or head. Every movement will be executed by python code that bundled inside choregraphe (refer to Figure 5). 


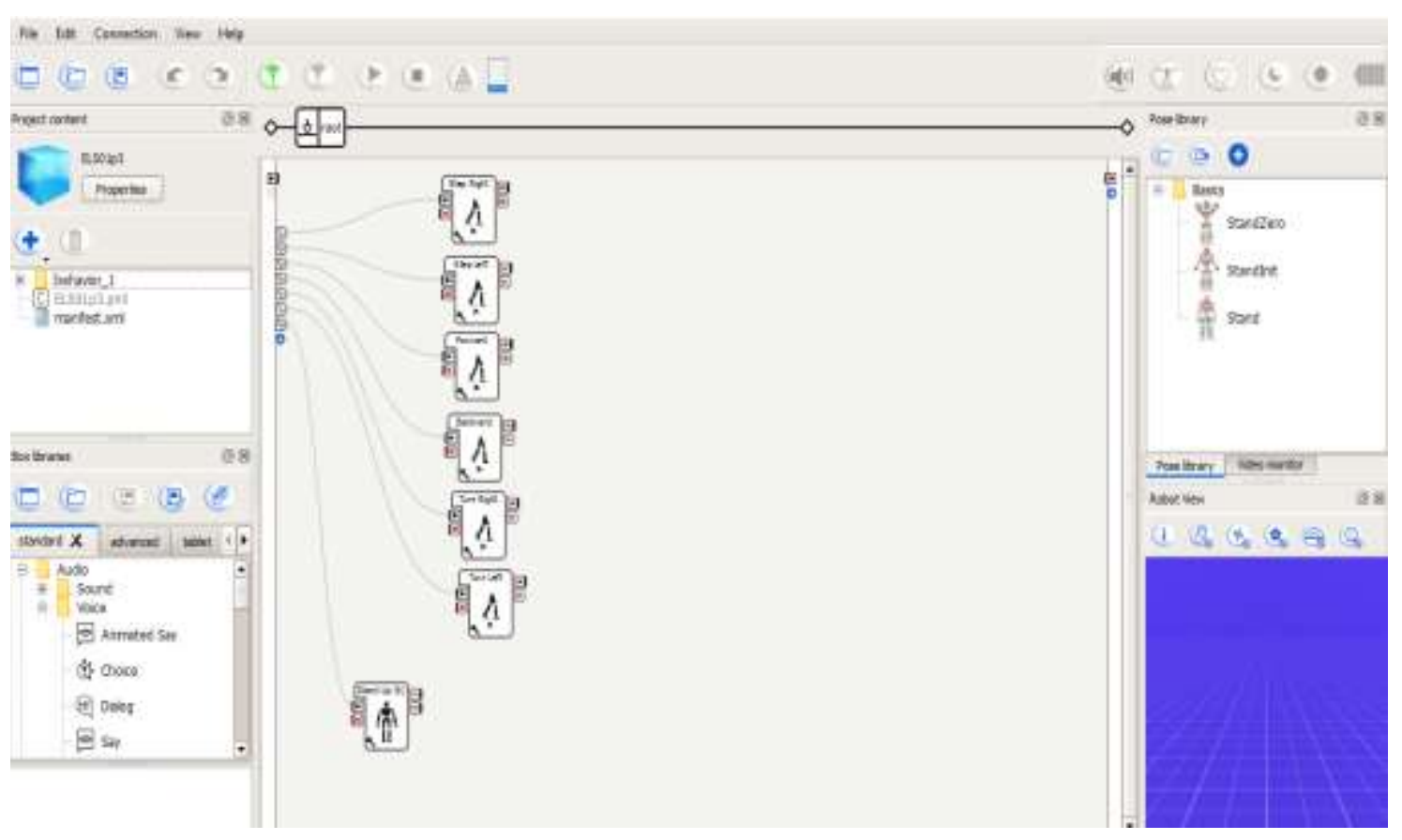

Figure 4. Choregraphe design Nao Interaction

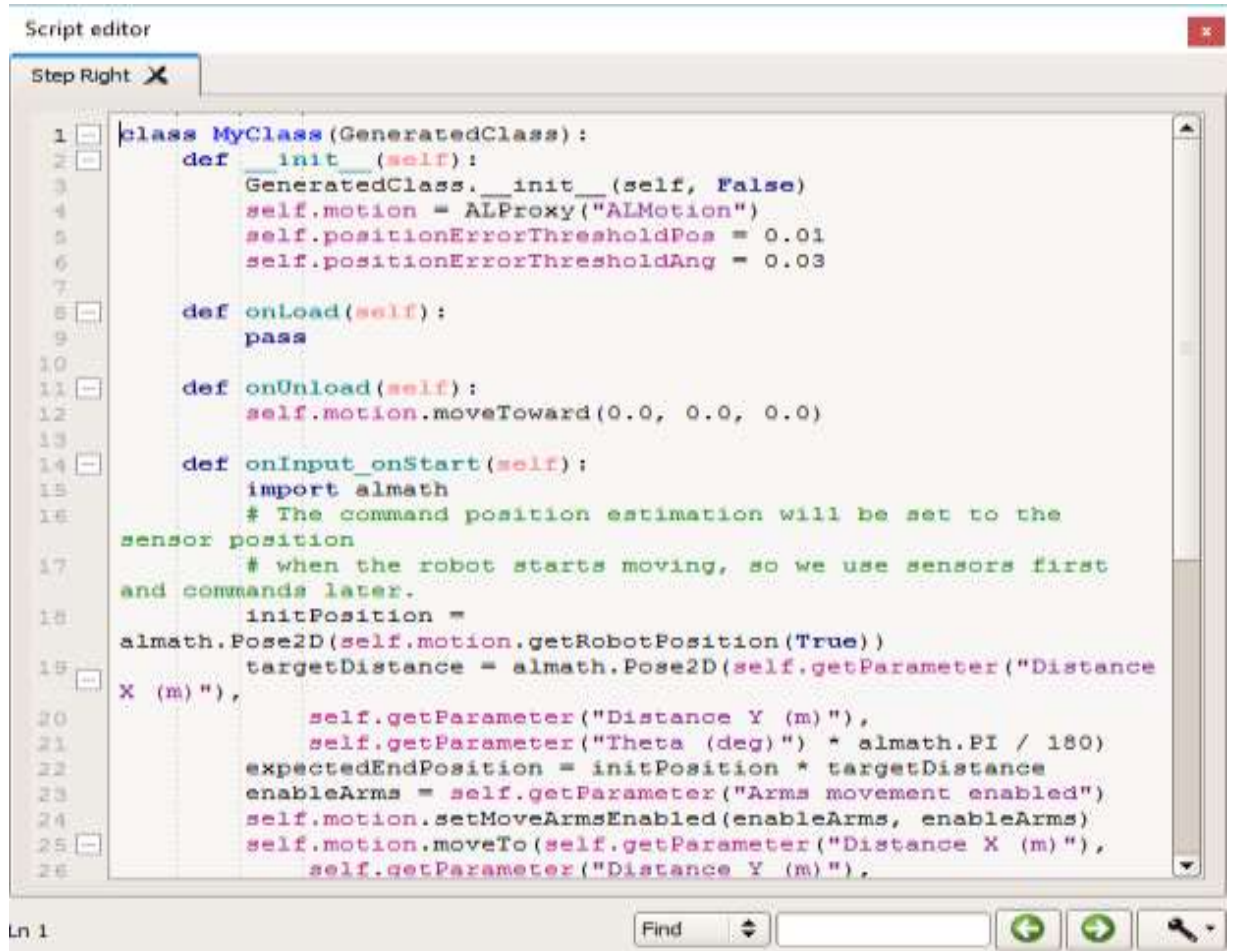

Figure 5. Phyton Code for NAO motion control

\subsection{Handwriting Recognition}

There are several steps for the handwriting recognition such as:

a) Preprocessing

b) Segmentation

c) Feature Extraction

d) Classification 
Pre-processing phase can be divided into several stages:

a) "Size normalization": This stage used to edit the image and the size standard using "Bicubic interpolation".

b) "Binarization": Convert the grayscale image into binary image by thresholding technique

c) "Smoothing": Reduce the broken edge of the image

d) "Edge detection": Method to detect the boundary of image by comparing with neighbouring intensity.

After scanning the character, the image is under "pre-processing" stage that will remove the noise, and "binarization" in order to produce text from image. The image from "pre-processing" stage is classififed into lines, words and characters. Explanation is given to the below.

a) Segmentation of Line: isolate line from text

b) Segmentation of Word: parsing and isolate between word to word

c) Character Recognition: neural network is used to recognised the letter.

We used phyton based neural network for character recognition because it has the same platform as NAO choregraphe engine. The result of character recognition is shown in Figure 6. The basic calculation of the neural network to find optimum weight and biases can be computed through cost function (1) [25]:

$$
C(\omega, b) \equiv \frac{1}{2 n} \sum\|y(x)-a\|^{2}
$$

$\omega$ denotes weights, $b$ is the biases, $n$ is number of training, a is vector of output if $x$ is input.
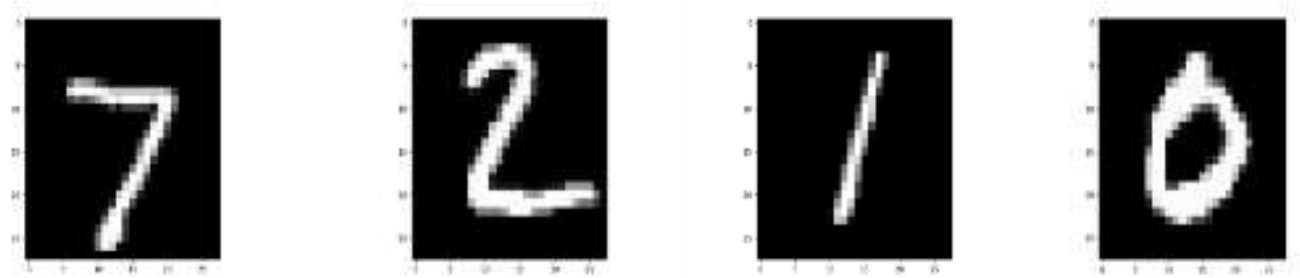

Figure 6. Recognized handwriting character

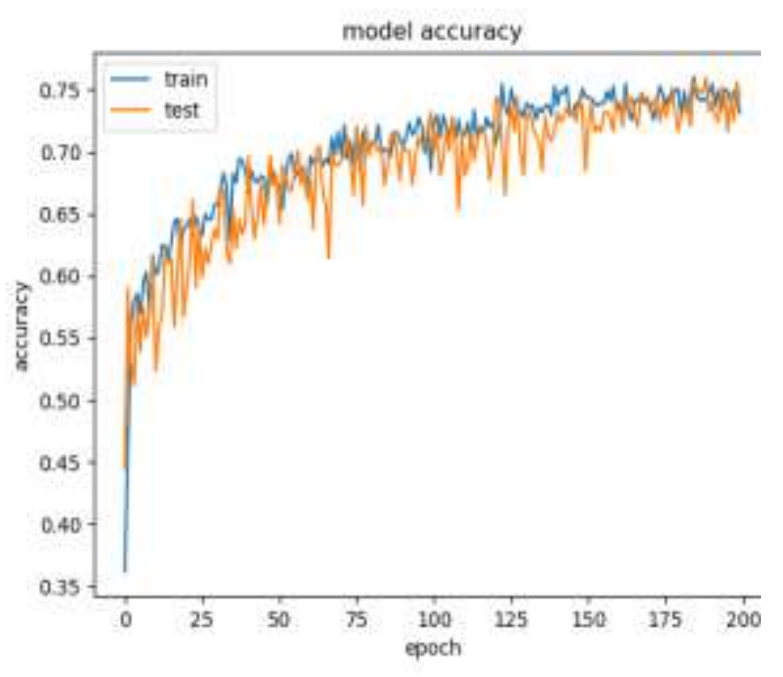

(a)

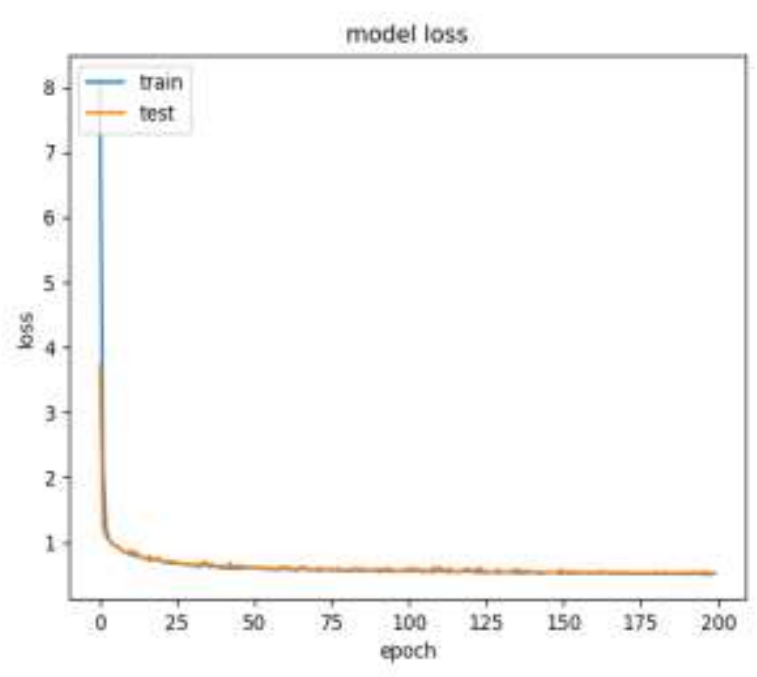

(b)

Figure 7. Recognition Evaluation

The hand writing database is used based on MNIST database [26]. Figure 7 shows the recognition result is quite promising when its reach $75 \%$ recognition rate and the loss value less than 0.6 . Its can be achieved due to we ask the kids to write the character on the blank white paper to ease NAO recognize the handwriting. The children are quite sophisticated and happy to follow the character pronunciation of NAO. 


\section{CONCLUSION}

The learning with robots are interesting for kids; the content of play and fun are affecting the result of the learning process. Kids are motivated by touch my head game, where they can study to listen to instruction and conduct the task properly. The character recognition also plays an important role, how NAO recognises the kids writing, and it can be spelt back towards them. In this case, the kids can learn how to pronounce English much better. The robot was able to achieve a high recognition rate for $75 \%$ for Kid's handwritten. The testing accuracy is raising since the beginning of epoch and reach more than $75 \%$ during the 200 cycles, while loss rates are similar between the training and testing phase. It means The NAO can predict ad capture the information written by a kid. As future works, a lot of features that can be added later on, especially the interaction can produce through a more complicated game for learning.

\section{ACKNOWLEDGEMENTS}

This work was supported by the Department of Information Technology, Faculty of Computing and Information technology Rabigh, King Abdulaziz University, Rabigh, Makkah Saudi Arabia. The authors, therefore, gratefully acknowledge the FCITR technical support.

\section{REFERENCES}

[1] IFR. (2018, 25 October). World Robotics Survey:Service robots are conquering the world. Available: https://ifr.org/news/world-robotics-survey-service-robots-are-conquering-the-world-/

[2] J. Han, et al., "Comparative study on the educational use of home robots for children," Journal of Information Processing Systems, vol. 4, pp. 159-168, 2008.

[3] D. Lees and P. LePage, "Robots in education: the current state of the art," Journal of Educational Technology Systems, vol. 24, pp. 299-320, 1996.

[4] F. B. V. Benitti, "Exploring the educational potential of robotics in schools: a systematic review," Computers and Education, vol. 58, pp. 978-988, 2012.

[5] U. Qidwai, et al., "Humanoid Robot as a Teacher's Assistant: Helping Children with Autism to Learn Social and Academic Skills," Journal of Intelligent \& Robotic Systems, vol. 1, 2019.

[6] J. Han and D. Kim, "r-Learning services for elementary school students with a teaching assistant robot," in The 4th ACM/IEEE International Conference on Human-Robot Interaction (HRI), La Jolla, CA, 2009, pp. 255-256.

[7] J. H. Han, et al., "Physical learning activities with a teaching assistant robot in elementary school music class," Journal of Convergence Information Technology, vol. 5, pp. 1406-1410, 2009.

[8] K. Highfield, et al. (2008, 1-11-2019). Early mathematics learning through exploration with programable toys. Available: http://hdl.handle.net/1959.14/322176

[9] F. Jamet, et al., "Learning by Teaching with Humanoid Robot: A New Powerful Experimental Tool to Improve Children's Learning Ability," Journal of Robotics, vol. 2018, pp. 1-11, 2018.

[10] S. Y. Okita, et al., "Learning together: ASIMO developing an interactive learning partnership with children," in The 18th IEEE International Symposium on Robot and Human Interactive Communication, 2009, pp. 1125-1130.

[11] T. Balch, et al., "Designing personal robots for education: hardware, software, and curriculum," IEEE Pervasive Computing, vol. 7, pp. 5-9, 2008.

[12] O. Mubin, et al., "Improving speech recognition with the robot interaction language," Disruptive Science and Technology, vol. 1, pp. 79-88, 2012.

[13] D. Belanche, et al., "Service robot implementation: a theoretical framework and research agenda," The Service Industries Journal, vol. 40, pp. 203-225, 2020/03/11 2020.

[14] I. Jawaid, et al., "Robotic system education for young children by collaborative project based learning," Comput Appl Eng Educ, vol. 28, pp. 178-192, 2020.

[15] M. Saerbeck, et al., "Expressive robots in education: varying the degree of social supportive behavior of a robotic tutor," in CHI Conference on Human Factors in Computing Systems, Atlanta Georgia USA, 2010, pp. 1613-1622.

[16] R. Mitnik, et al., "An autonomous educational mobile robot mediator," Autonomous Robots, vol. 25, pp. 367-382, 2008/11/01 2008.

[17] C.-W. Chang, et al., "Exploring the Possibility of Using Humanoid Robots as Instructional Tools for Teaching a Second Language in Primary School," Educational Technology \& Society, vol. 13, pp. 13-24, 2010.

[18] N. Abdullasim, et al., "Velocity Perception: Collision Handling Technique for Agent Avoidance Behavior," Telkomnika, vol. 11, 2013.

[19] N. N. Albaqami, et al., "Augmenting Pilgrim Experience and Safety with Geo-location Way finding and Mobile Augmented Reality," International Journal of Computer Science and Network Security, vol. 8, pp. 23-32, 2018.

[20] H. M. A. AlJahdali and A. H. Basori, "Emotional Contagion Driven of Parent-Child's Agents in Crowd during Panic Situation," International Journal of Computer Network and Information Security, vol. 19, pp. 261-266, 2019.

[21] A. H. Basori, "Emotion Walking for Humanoid Avatars Using Brain Signals," International Journal of Advanced Robotic Systems, vol. 10, p. 29, 2013/01/01 2013.

[22] A. H. Basori and H. M. A. AlJahdali, "Performance Driven-biped Control for Animated Human Model with Motion Synthesis Data," Journal of Information Systems Engineering and Business Intelligence, vol. 4, 2018.

[23] Alysis. (2019, November). Nao Sensor. Available: https://www.alisys.net/en/robot-nao 
[24] Aldebaran. (2019, November). NAO Actuator and Sensor. Available: http://doc.aldebaran.com/21/family/nao_dcm/actuator_sensor_names.html

[25] M. A. Nielsen, Neural networks and deep learning: Determination press USA, 2015.

[26] Y. LeCun. (1998, The MNIST database of handwritten digits. Available: http://yann.lecun.com/exdb/mnist

\section{BIOGRAPHIES OF AUTHORS}

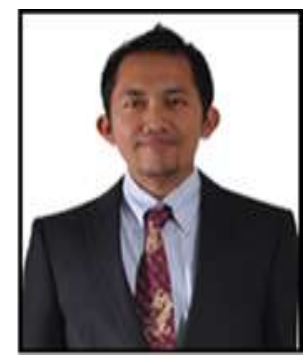

Ahmad Hoirul Basori, received B.Sc (Software Engineering) degree from Institut Teknologi Sepuluh Nopember Surabaya in 2004 and the Ph.D (Computer Graphics) from Universit Teknologi Malaysia, Johor Bahru, Johor, in 2011. In 2011, he has appointed as Assistant Professor with the Department of Computer Graphics and Multimedia, Universiti Teknologi Malaysia. In 2016, he is promoted to Associate Professor rank in Faculty of Computing and Information Technology Rabigh, King Abdulaziz University. He is the member of Editorial board of some international journal, and published more than 80 articles. He is also a member of professional membership IEEE, ACM SIGGRAPH, IAENG and Senior Member of IACSIT. His research interests include Computer Graphics, Facial Animation, Cloth Simulation, Medical Visualization, Haptic Interaction, Man Machine Interaction and Robotics. 